\title{
MATHEMATICAL MODEL OF A VAPOUR ABSORPTION REFRIGERATION UNIT
}

\author{
Micallef, D. \& Micallef, C. \\ University of Malta, Department of Mechanical Engineering, Msida, MSD 2080 Malta \\ E-Mail: dmic0001@um.edu.mt
}

\begin{abstract}
By means of carefully devised assumptions, a simple linear model is presented for an absorption refrigeration unit employing either water-lithium bromide or ammonia-water refrigerant-absorbent pairs. Absorption systems are an alternative to vapour compression systems by being thermally activated. Such heat energy may come from the sun or even from hot exhaust gases from a particular engineering process. A thorough investigation of the optimal operating temperatures is necessary to ensure effective operation of the system. By means of this simulation, the system response to varying absorber, generator and condenser temperatures was analyzed.

(Received in October 2009, accepted in March 2010. This paper was with the authors 1 month for 1 revision.)
\end{abstract}

Key Words: Refrigeration, Absorption Systems, Water-Lithium Bromide, Ammonia-Water

\section{INTRODUCTION}

Vapour compression refrigeration units require a high grade energy input in the form of work by means of an electrically driven compressor. This leads to higher power demands from power stations which in turn lead to more $\mathrm{CO}_{2}$ emissions.

Absorption systems use a low grade form of energy in order to provide a cooling effect. This means that the source of input energy need not necessarily come from electric power but rather from any other heat source which is at a sufficiently high temperature. Apart from being advantageous from this perspective of energy use, such systems also provide other advantages over vapour compression refrigeration units employing compressors. For example, their silent operation is unmatched when compared to the latter systems.

As absorption units become more popular not only in industry but also on a domestic level, their simulation becomes more important. This enables better understanding of the complex thermodynamic behaviour which such systems exhibit. Various mathematical models have been created in the past [1-2]. Much of the focus of these studies was put on systems using water-lithium Bromide $\left(\mathrm{LiBr}-\mathrm{H}_{2} \mathrm{O}\right)$ refrigerant-absorbent pair. Analysis of these systems has also been extended to multi effect units.

Nowadays, the investigation of ammonia-water $\left(\mathrm{H}_{2} \mathrm{O}-\mathrm{NH}_{3}\right)$ systems is becoming more important especially with the introduction of efficient Generator-Absorber Heat Exchange (GAX) absorption units. Although the latter systems are in principle the same, they require additional devices which in themselves require thermodynamic modelling.

In this work, a simulation of single-effect absorption was performed. The working fluids which can be modelled are $\mathrm{LiBr}-\mathrm{H}_{2} \mathrm{O}$ and $\mathrm{H}_{2} \mathrm{O}-\mathrm{NH}_{3}$. The developed mathematical model, being linear, can be easily extended to model double or multi-effect systems. This however will be done in future work. By means of certain user inputs, the model calculates output parameters which are of fundamental importance for the analysis of these systems. Relationships between input and output parameters may be plotted automatically for better visualization of the system behaviour. A secondary aim of the simulation was to be able to aid 
system designers in the design of the most fundamental components. In particular, it is possible to find (in a relatively crude manner) the solar panel area required for a certain refrigeration effect given the relevant system temperatures. Similar work was performed by V. Mital et al. [3] were a similar model was used but which could only employ $\mathrm{LiBr}-\mathrm{H}_{2} \mathrm{O}$ as the refrigerant-absorbent pair.

\section{ABSORPTION SYSTEM PRINCIPLES}

Whereas vapour compression cycles require a compressor in order to do work on the refrigerant, vapour absorption cycles replace this unit with other components for the purpose of inputting heat energy from a suitable source. The most basic components of a vapour absorption cycle are the evaporator, absorber, pump(s), generator (or desorber), a condenser and throttle valves [4-5].

The compressor is replaced by the absorber, pump, generator and an optional heat exchanger which is generally known as the solution heat exchanger (SHX). Another difference from vapour compression cycles is that this system, apart from the refrigerant, makes use of an absorbent fluid. Fig. 1 depicts simplified absorption cycles employing different absorbent-refrigerant pairs. The evaporator-condenser part of the system is not different from that of vapour compression systems. The absorber-generator part however consists of the above mentioned units. In the absorber, the absorbent fluid absorbs within it the refrigerant in the vapour phase, with the consequence of heat release. The refrigerantabsorbent mixture is then transferred to the generator via a pump. In this unit, heat is transferred to the mixture in order to drive off the refrigerant from the mixture, leaving behind a weak mixture (low percentage of refrigerant) which is transferred back to the absorber via a throttle valve. As the refrigerant-absorbent mixture is pumped to the generator some heat may be gained from the weak mixture leaving the generator through a solution heat exchanger. This greatly enhances the Coefficient of Performance (COP) of the system.

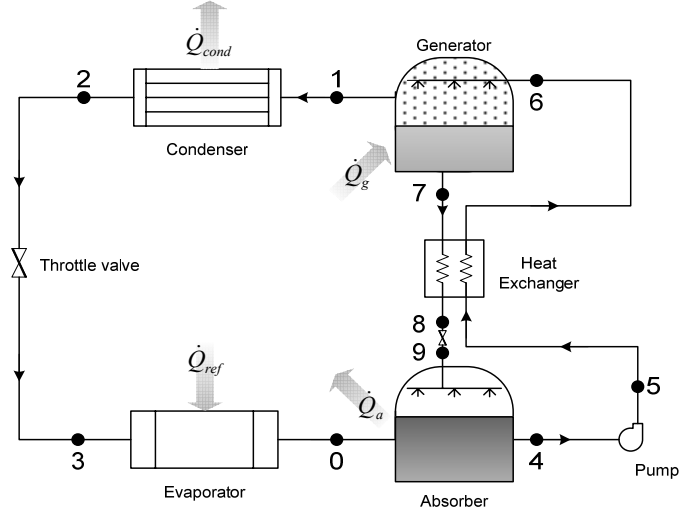

(a)

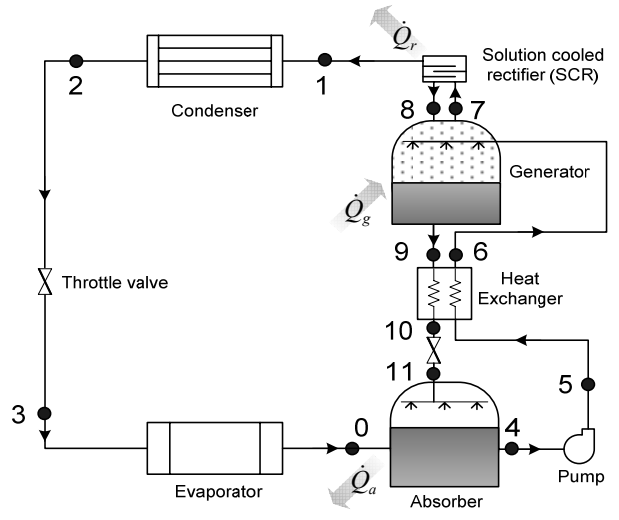

(b)

Figure 1: a) Lithium Bromide-water, b) Water-ammonia vapour absorption systems.

The pumps required in this system consume a minute amount of power compared to compressors and this is usually ignored in most engineering analysis, including the mathematical model proposed in this work. In vapour compression the energy input is of a high quality (shaft power), in vapour absorption on the other hand the energy input is in the form of heat from a source at a suitable temperature. It is therefore possible to use any source provided the temperature is high enough. These sources of heat may come from the burning of natural gas, waste heat from a particular process or say from solar heating of a secondary fluid. 
The absorbent-refrigerant part need not necessarily be lithium bromide and water. Water may instead be used as the absorbent and ammonia as the refrigerant. Such systems tend to be more complex primarily due to the volatility of the absorbent which requires the use of a rectifier column which separates the absorbent from the refrigerant. Also, lower COP values are achieved compared to $\mathrm{LiBr}-\mathrm{H}_{2} \mathrm{O}$ units. One major advantage is that ammonia can reach sub-zero temperatures [4]. The mathematical relationships used to model absorption systems are based on mass and energy conservation and take the following form:

$$
\begin{gathered}
\sum_{i} \dot{m}_{i}=0 \\
\sum \dot{m}_{\text {in }} h_{\text {in }}+\sum \dot{Q}=\sum \dot{m}_{\text {out }} h_{\text {out }}
\end{gathered}
$$

where $\dot{m}$ is the mass flow rate $(\mathrm{kg} / \mathrm{s}), h$ is the specific enthalpy $(\mathrm{kJ} / \mathrm{kg})$ and $\dot{Q}$ is the heat transfer rate $(\mathrm{W})$.

\section{THE MATHEMATICAL MODEL}

All of the equations derived from the thermodynamic analysis of absorption systems can be written in the form of functions as follows:

$$
\begin{gathered}
\varphi_{1}\left(x_{1}, x_{2}, x_{3}, \ldots, x_{\beta}\right)=0 \\
\varphi_{2}\left(x_{1}, x_{2}, x_{3}, \ldots, x_{\beta}\right)=0 \\
\varphi_{3}\left(x_{1}, x_{2}, x_{3}, \ldots, x_{\beta}\right)=0 \\
\vdots \\
\varphi_{\lambda}\left(x_{1}, x_{2}, x_{3}, \ldots, x_{\beta}\right)=0
\end{gathered}
$$

where $x_{1}, x_{2}, x_{3}, \ldots, x_{\beta}$ are the unknown variables. Also, $\beta$ is the number of unknown variables while $\lambda$ is the number of equations.

For the system of equations to be determinate, $\beta=\lambda$. In general, if system (3) is to be solved as a whole the problem would be non-linear. However since energy and mass conservation equations are uncoupled the problem is reduced to linear form.

The system matrix [S] will be defined for the purpose of this model, as the combined set of thermodynamic/mass balance coefficients for a particular absorption system. This matrix is therefore composed of two sets of coefficients. The first system of linear equations defining mass balance coefficients would be mass balance equations while the second system of equations would give energy balance coefficients (both sets are independent of each other). Thus, if we assume some constant coefficients for those non-linear equations (made of product terms) we can combine both systems into one matrix [S] and easily solve for all of the unknowns:

$$
\{x\}=[S]^{-1}\{b\}
$$

where $\{b\}$ represents the vector of terms of the right hand side of the equations. If there exist such non-linear equations, the procedure would then involve two iterations. The first iteration would enable calculation of the correct values for the linear mass balance equations. Mathematically for some initial system matrix $\left[\mathrm{S}_{0}\right]$ :

$$
\left\{x_{0}\right\}=\left[S_{0}\right]^{-1}\{b\}
$$


At this stage, the energy quantities obtained would have to be corrected. By means of Eq. (5) the correct coefficient can be found which through a second iteration would enable us to find correct values for the energy quantities which form part of the originally non-linear equations. Thus Eq. (4) may be used to find the final corrected values. As an example a $\mathrm{LiBr}-$ $\mathrm{H}_{2} \mathrm{O}$ system without using a heat exchanger as shown in Fig. 2 is used. In this case only one iteration is required since all of the equations are linear. The major assumptions used in the model are the following:

- Refrigerant is just saturated at exit from the evaporator.

- Specific enthalpy of superheated refrigerant at inlet of condenser from generator is equal to the specific enthalpy of saturated refrigerant at the generator temperature.

- Solutions leaving the absorber and generator are saturated at the unit temperature.

- Absorber and generator pressures are equal to the evaporator and condenser respectively.

- Solution entering generator is at the generator pressure.

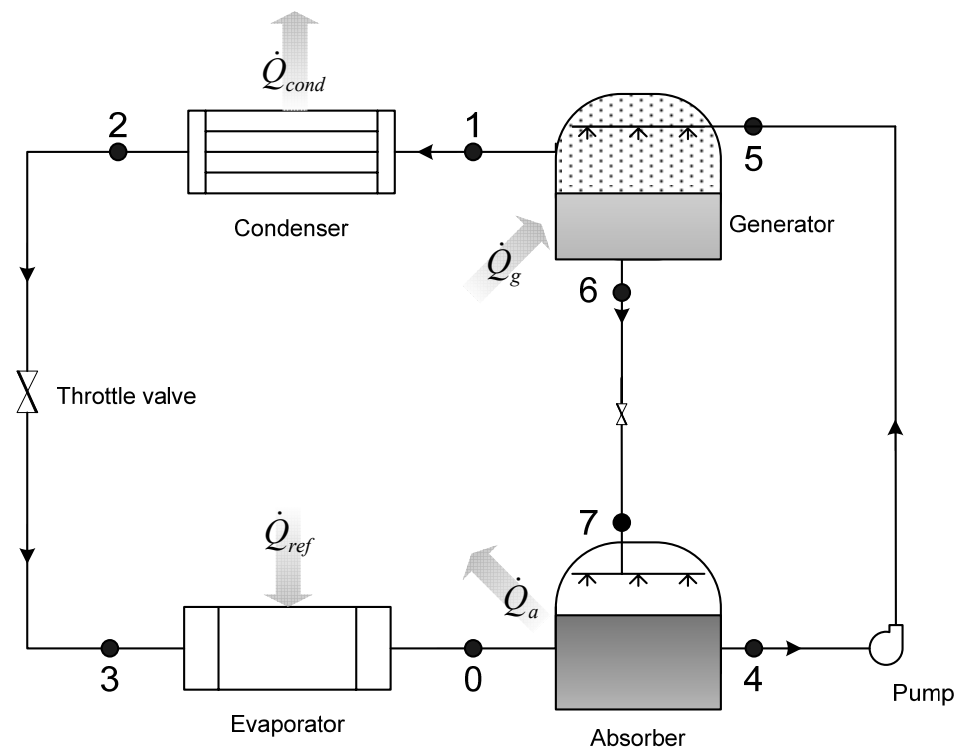

Figure 2: $\mathrm{LiBr}-\mathrm{H}_{2} \mathrm{O}$ system without a heat exchanger.

The trivial equations need to be solved prior solving for the rest of the quantities.

Throttling processes:

$$
h_{3}=h_{2} \text { and } h_{7}=h_{6}
$$

Pump:

$$
h_{5}=h_{4}
$$

Evaporator:

$\dot{m}_{0}=\dot{m}_{1}=\dot{m}_{2}=\dot{m}_{3}=\dot{Q}_{\text {ref }} /\left(h_{0}-h_{3}\right)$

Condenser:

$\dot{Q}_{\text {cond }}=\dot{m}_{1}\left(h_{2}-h_{1}\right)$

Low concentration line:

$$
C_{5}=C_{4}
$$

High concentration line:

$$
C_{7}=C_{6}
$$

where $C=\mathrm{LiBr}$ concentration (found from data for fluid properties, $h=$ specific enthalpy, $\dot{Q}_{a}=$ absorber heat rejected and $\dot{Q}_{g}=$ generator heat input. The non-trivial equations are:

Pump mass balance: $\quad \dot{m}_{4}-\dot{m}_{5}=0$

Throttle valve mass balance: $\dot{m}_{6}-\dot{m}_{7}=0$ 
Generator solution mass balance: $\dot{m}_{5}-\dot{m}_{6}=\dot{m}_{1}$

Generator absorbent mass balance: $C_{5} \dot{m}_{5}-C_{6} \dot{m}_{6}=0$

Absorber energy balance: $-\dot{m}_{4} h_{4}+\dot{m}_{7} h_{7}-\dot{Q}_{a}=-\dot{m}_{0} h_{0}$

Generator energy balance: $\dot{m}_{5} h_{5}-\dot{m}_{6} h_{6}+\dot{Q}_{g}=\dot{m}_{1} h_{1}$

Using Eq. (4)

$$
\left[\begin{array}{cccccc}
1 & -1 & 0 & 0 & 0 & 0 \\
0 & 0 & 1 & -1 & 0 & 0 \\
0 & 1 & -1 & 0 & 0 & 0 \\
0 & C_{5} & -C_{6} & 0 & 0 & 0 \\
-h_{4} & 0 & 0 & h_{7} & -1 & 0 \\
0 & h_{5} & -h_{6} & 0 & 0 & 1
\end{array}\right]\left\{\begin{array}{l}
\dot{m}_{4} \\
\dot{m}_{5} \\
\dot{m}_{6} \\
\dot{m}_{7} \\
\dot{Q}_{a} \\
\dot{Q}_{g}
\end{array}\right\}=\left\{\begin{array}{c}
0 \\
0 \\
\dot{m}_{1} \\
0 \\
\dot{m}_{0} h_{0} \\
m_{1} h_{1}
\end{array}\right\}
$$

\section{MODEL IMPLEMENTATION}

The proposed mathematical model was implemented by writing a computer program using Microsoft ${ }^{\circledR}$ Visual Basic.NET. The software, Solabsorb $₫$, gives useful numerical data regarding a single effect absorption refrigeration unit which makes use of $\mathrm{LiBr}-\mathrm{H}_{2} \mathrm{O}$ or $\mathrm{NH}_{3}$ $\mathrm{H}_{2} \mathrm{O}$ absorbent-refrigerant pairs. In its most basic use, Solabsorb enables system designers to input certain design conditions from which information can be obtained regarding the operating conditions of the system including for example COP. This data can be plotted easily by the user by using the in built graph generator. Other features of the program include:

- Possibility of plotting the thermodynamic cycles on suitable charts.

- Access to the thermodynamic fluid properties of the $\mathrm{LiBr}-\mathrm{H}_{2} \mathrm{O}$ and $\mathrm{H}_{2} \mathrm{O}-\mathrm{NH}_{3}$ pairs.

- A design tool which gives rough but useful design estimates for the design of the units making up the system.

Fig. 3 shows the algorithm for the fundamental part of the simulation. The parameters which need to be input are the evaporator temperature or pressure, condenser temperature or pressure, absorber and generator temperature, the refrigeration capacity of the refrigerator as well as any under-cooling of the refrigerant at exit from the condenser. From these inputs, the fluid properties are read from a database. This database was constructed from graphical data found in [5] and [6] for the $\mathrm{LiBr}-\mathrm{H}_{2} \mathrm{O}$ and $\mathrm{NH}_{3}-\mathrm{H}_{2} \mathrm{O}$ solutions respectively. The mathematical procedure described in the previous section then follows until all unknown quantities are solved for.

\section{MODEL VALIDATION}

To verify the correctness of the results obtained from the simulation a comparison was made were [5] was used for a worked out numerical example and validation was performed. The problem involves the following system requirements:

- Single effect $\mathrm{LiBr}-\mathrm{H}_{2} \mathrm{O}$ with and then without a heat exchanger.

- Refrigeration capacity $=100 \mathrm{~kW}$.

- Evaporator temperature $=3^{\circ} \mathrm{C}$. 
- Condenser temperature $=34^{\circ} \mathrm{C}$.

- Absorber temperature $=25^{\circ} \mathrm{C}$.

- Generator temperature $=80^{\circ} \mathrm{C}$.

- No under cooling.

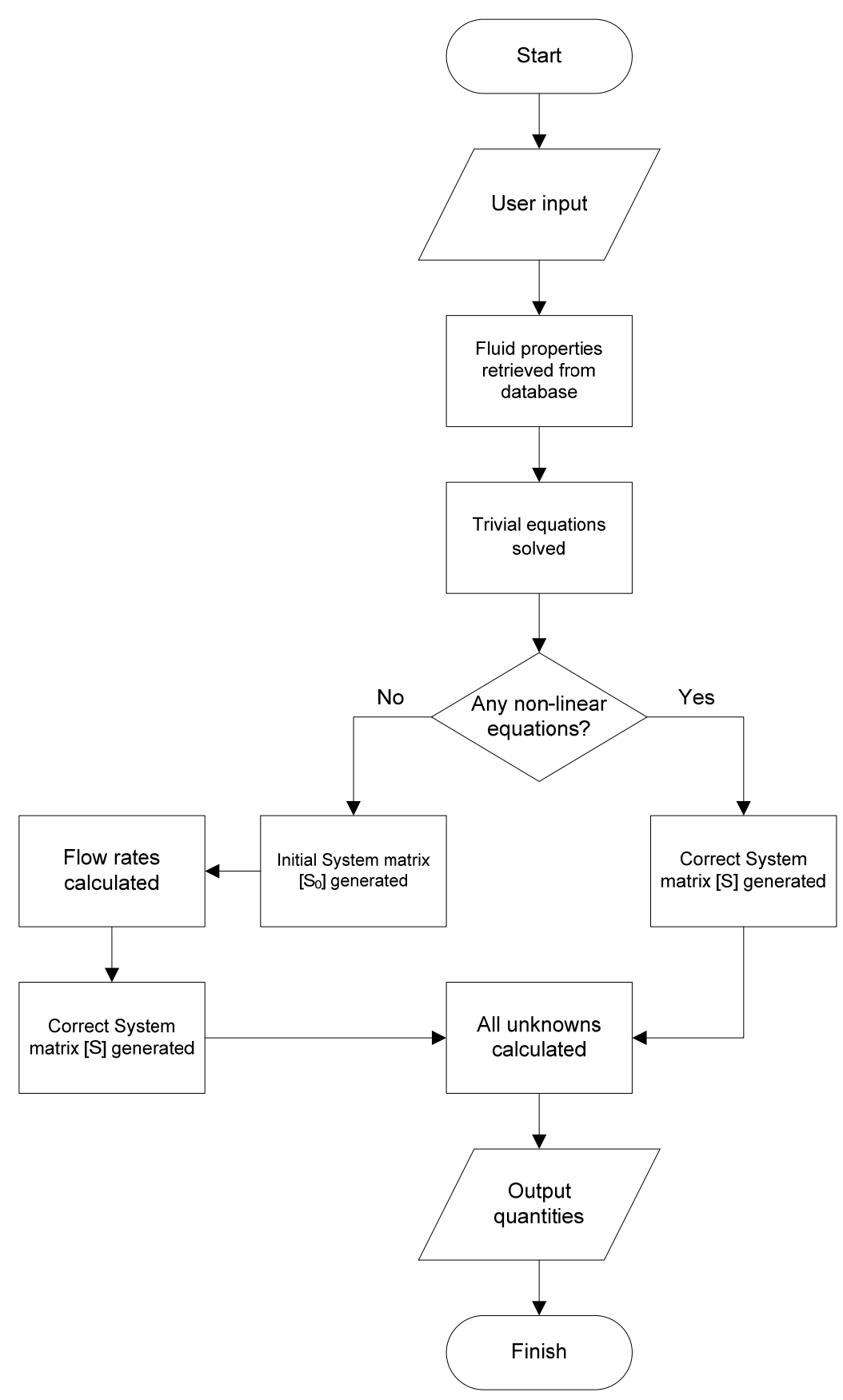

Figure 3: Algorithm for obtaining the output quantities of interest.

The given information was input in the main window of the Solabsorb software and the system was solved. Table I gives a comparison between the values as calculated from the authors [5] and those obtained with the mathematical model. The percentage error is also given. 
Table I: Comparison of results for $\mathrm{LiBr}-\mathrm{H}_{2} \mathrm{O}$ system with heat exchanger (Generator heat supply also calculated for no heat exchanger).

\begin{tabular}{|l|r|r|r|}
\hline Quantity & $\begin{array}{r}\text { Value obtained } \\
\text { by authors }\end{array}$ & $\begin{array}{r}\text { Value obtained } \\
\text { from simulation }\end{array}$ & Percentage error \\
\hline $\begin{array}{l}\text { Solution concentration at } \\
\text { absorber exit }\end{array}$ & 0.51 & 0.509 & $-0.20 \%$ \\
\hline $\begin{array}{l}\text { Solution specific enthalpy at } \\
\text { absorber exit }\end{array}$ & $-185 \mathrm{~kJ} / \mathrm{kg}$ & $-184.7 \mathrm{~kJ} / \mathrm{kg}$ & $+0.16 \%$ \\
\hline $\begin{array}{l}\text { Solution concentration at } \\
\text { generator exit }\end{array}$ & 0.60 & 0.61 & $+1.67 \%$ \\
\hline $\begin{array}{l}\text { Solution specific enthalpy at } \\
\text { generator exit }\end{array}$ & $-88.0 \mathrm{~kJ} / \mathrm{kg}$ & $-89.5 \mathrm{~kJ} / \mathrm{kg}$ & $-1.70 \%$ \\
\hline Refrigerant mass flow rate & $0.0423 \mathrm{~kg} / \mathrm{s}$ & $0.0423 \mathrm{~kg} / \mathrm{s}$ & $0.00 \%$ \\
\hline $\begin{array}{l}\text { Solution mass flow rate in low } \\
\text { concentration line }\end{array}$ & $0.2876 \mathrm{~kg} / \mathrm{s}$ & $0.2569 \mathrm{~kg} / \mathrm{s}$ & $-10.67 \%$ \\
\hline $\begin{array}{l}\text { Solution mass flow rate in } \\
\text { high concentration line }\end{array}$ & $0.2397 \mathrm{~kg} / \mathrm{s}$ & $0.2146 \mathrm{~kg} / \mathrm{s}$ & $-10.47 \%$ \\
\hline $\begin{array}{l}\text { Solution specific enthalpy } \\
\text { entering absorber }\end{array}$ & $-185.2 \mathrm{~kJ} / \mathrm{kg}$ & $-189.7 \mathrm{~kJ} / \mathrm{kg}$ & $-2.43 \%$ \\
\hline Heat rejected in absorber & $-114.82 \mathrm{~kW}$ & $-112.76 \mathrm{~kW}$ & $-1.79 \%$ \\
\hline $\begin{array}{l}\text { Heat supplied in generator } \\
\text { (with heat exchanger) }\end{array}$ & $120.60 \mathrm{~kW}$ & $118.56 \mathrm{~kW}$ & $-1.69 \%$ \\
\hline $\begin{array}{l}\text { Heat supplied in generator (no } \\
\text { heat exchanger) }\end{array}$ & $143.92 \mathrm{~kW}$ & $140.07 \mathrm{~kW}$ & $-2.68 \%$ \\
\hline COP for refrigeration & 0.83 & 0.84 & $+1.20 \%$ \\
\hline
\end{tabular}

The authors take the properties of the solution graphically from the enthalpy-concentration chart. On the other hand with the simulation linear interpolation of data (from a database) was used. This causes a discrepancy in both solution concentrations as well as enthalpies. Of course, all other values are affected by the error inherent in these quantities. Particularly, the solution mass flow rate in low concentration line and solution mass flow rate in high concentration line are very sensitive to these errors and their discrepancy from the authors' calculated values are -10.67 per cent and -10.47 per cent respectively. These errors cause a slight error in the solution specific enthalpy entering the absorber calculated from an iterative process. The rest of the quantities are very accurate. Other validation tests (which are not shown here) were carried out and compared with similar simulations and good agreement was again obtained.

\section{RESULTS}

The response of the system to varying conditions could be studied and compared with the obtained results. The coefficient of performance of a hypothetical system was investigated as well as the absorber and generator heat transfers for given operating conditions. This can help in understanding better how to tweak the parameters to obtain optimal behaviour. Both $\mathrm{LiBr}-$ $\mathrm{H}_{2} \mathrm{O}$ and $\mathrm{H}_{2} \mathrm{O}-\mathrm{NH}_{3}$ systems operate at an evaporator temperature of $5^{\circ} \mathrm{C}$ and no condenser under-cooling. The heat transfers were found per $\mathrm{kW}$ of refrigeration capacity. 


\subsection{COP analysis}

The coefficient of performance is defined as follows:

$$
C O P=\frac{Q_{r e f}}{Q_{g}}
$$

where $Q_{r e f}$ is the refrigerating capacity ( $1 \mathrm{~kW}$ in this case) and $Q_{g}$ is the generator heat input. Fig. 4 shows how COP varies with absorber and generator temperature $\left(T_{a}\right.$ and $T_{g}$ respectively), for condenser temperatures of 30,40 and $50^{\circ} \mathrm{C}$, for a $\mathrm{LiBr}-\mathrm{H}_{2} \mathrm{O}$ system. The lower the $T_{a}$ and the higher the $T_{g}$ the better the system COP. For a condenser temperature of $30^{\circ} \mathrm{C}$ the system is operational for the entire range of temperatures shown. The simulation is capable of detecting such cases as for example crystallization of the absorbent fluid. The system performance seriously deteriorates from a COP maximum of about 0.75 at high generator and low absorber temperature to around 0.55 at low generator temperature and high absorber temperature. As the condenser temperature increases the system COP is reduced and non-operating regions can be observed in the high $T_{a}$ and low $T_{g}$ range. The condenser temperature seems to push the $T_{a}$ requirement further down and the $T_{g}$ requirement further up. A reduction of generator temperature is therefore a problem in a $\mathrm{LiBr}-\mathrm{H}_{2} \mathrm{O}$ unit for the evaporator temperature of $5^{\circ} \mathrm{C}$.

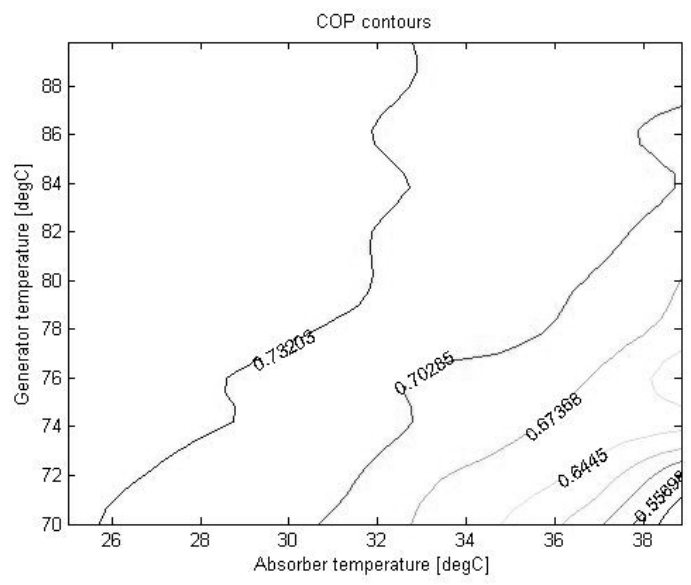

a)

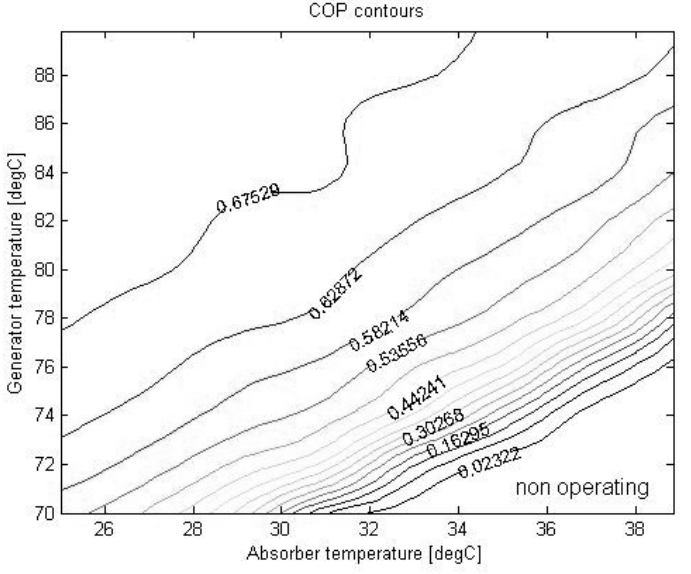

b)

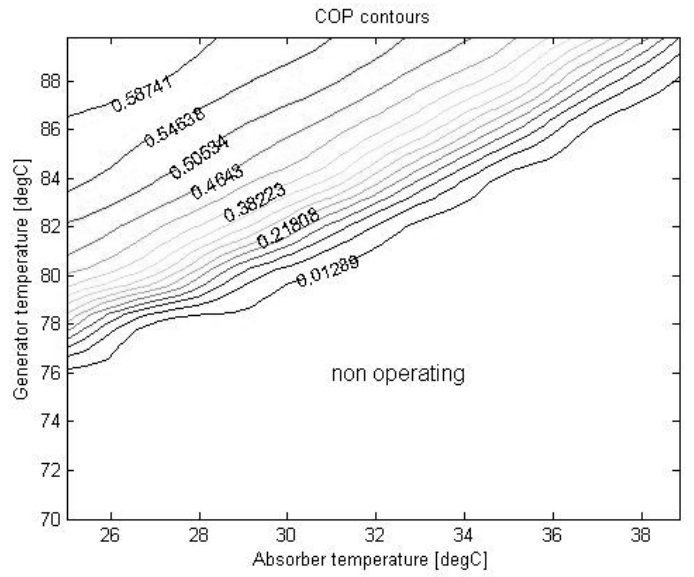

c)

Figure 4: $\mathrm{LiBr}-\mathrm{H}_{2} \mathrm{O}$ COP contours for different absorber and generator temperatures for condenser temperatures of a) $30^{\circ} \mathrm{C}$, b) $40^{\circ} \mathrm{C}$ and c) $50^{\circ} \mathrm{C}$. 
Fig. 5 shows the same situation but for an $\mathrm{H}_{2} \mathrm{O}-\mathrm{NH}_{3}$ refrigerant-absorbent pair. The system model in this case includes a rectifier heat exchanger which is necessary to effectively separate the absorbent from the refrigerant [7]. This time the situation is different as the contour lines appear to be more or less perpendicular to the contour lines for the $\mathrm{LiBr}-\mathrm{H}_{2} \mathrm{O}$ unit. This means that for a condenser temperature of $30^{\circ} \mathrm{C}$ the maximum COP can be observed at a low $T_{g}$ (rather than a high one) and at low $T_{a}$. Such trends have been observed in a similar simulation by Chaouachi et al. [8] where as generator temperature was increased the COP decreased for an evaporator temperature of $0^{\circ} \mathrm{C}$ and various condenser pressures. The COP limit of around 0.6 has also been observed by Kim et al. [9]. The reason for this behaviour, could be attributed to the increased loss of energy in the rectifier as generator temperature is increased causing a larger requirement in generator heat input and hence a reduction in COP. Further work in this regard should help to clarify this. For both cases it is always important to keep a low absorber temperature. The interesting behaviour is found when the condenser temperature is increased. The contour lines change direction and rotate in the clockwise direction tending towards the $\mathrm{LiBr}-\mathrm{H}_{2} \mathrm{O}$ case. This would mean that the heat loss from the rectifier is not too large as before. Therefore at a condenser temperature of $50^{\circ} \mathrm{C}$ (Fig. $5 \mathrm{c}$ ), a very low generator temperature might deteriorate the COP dramatically (dense contour lines showing sharp COP drop). Although the COP reduces by only a small amount for an increase in condenser temperature from 30 to $50^{\circ} \mathrm{C}$ the operation region becomes of utmost importance.

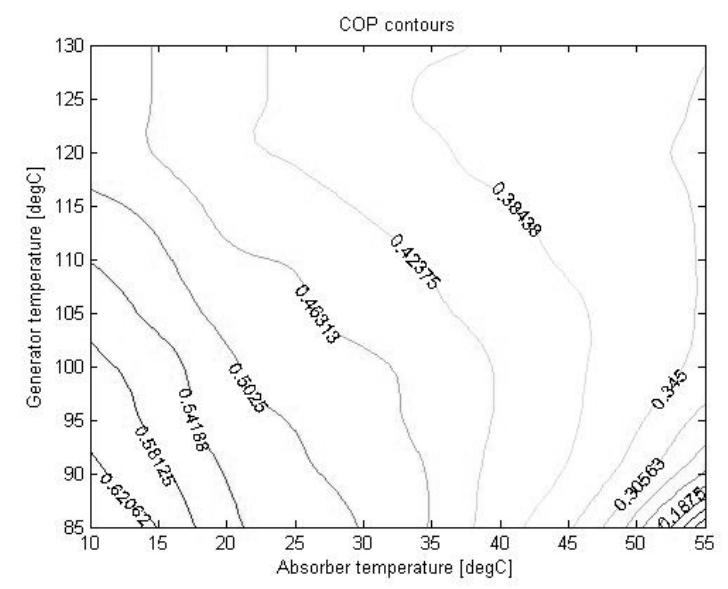

a)

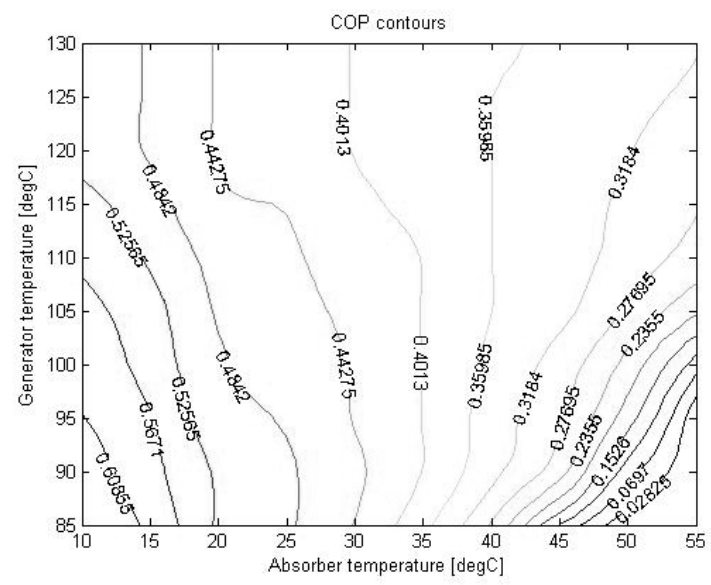

b)

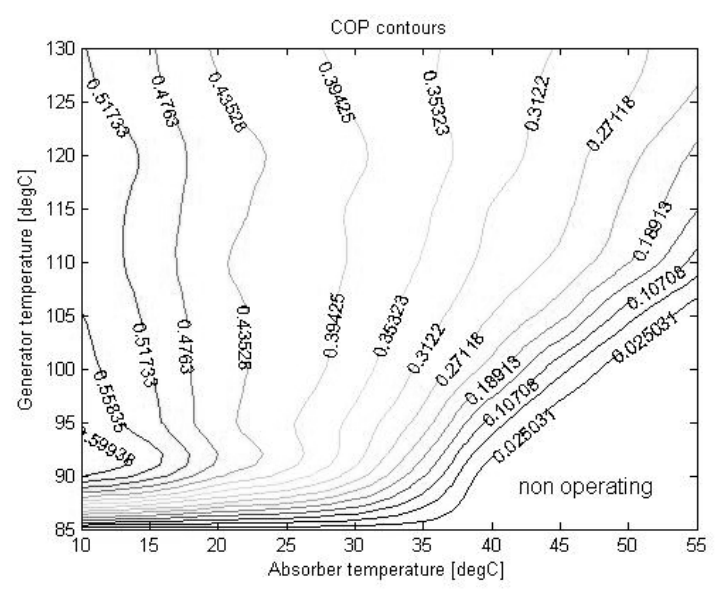

c)

Figure 5: $\mathrm{H}_{2} \mathrm{O}-\mathrm{NH}_{3}$ COP contours for different absorber and generator temperatures for condenser temperatures of a) $30^{\circ} \mathrm{C}$, b) $40^{\circ} \mathrm{C}$ and c) $50^{\circ} \mathrm{C}$. 


\subsection{Absorber and generator heat transfers}

For the analysis of the absorber and generator heat transfers, a condenser temperature of $30^{\circ} \mathrm{C}$ is used. For the $\mathrm{LiBr}-\mathrm{H}_{2} \mathrm{O}$ system, Fig. 6 shows absorber heat reject and generator heat input against absorber temperature and generator temperature respectively. Fig. 6a shows that a high absorber temperature not only reduces the COP but also increases the cooling requirements of the system. Therefore reducing absorber temperature has a twofold advantage. Provided that the generator temperature is not too low, the absorber heat rejection is not too sensitive to variations in generator temperature. In Fig. 6b large generator temperature reduces the heat input requirements (and hence increases COP). At low absorber temperatures the generator heat input is also not too sensitive to variation of the temperature in the absorber.

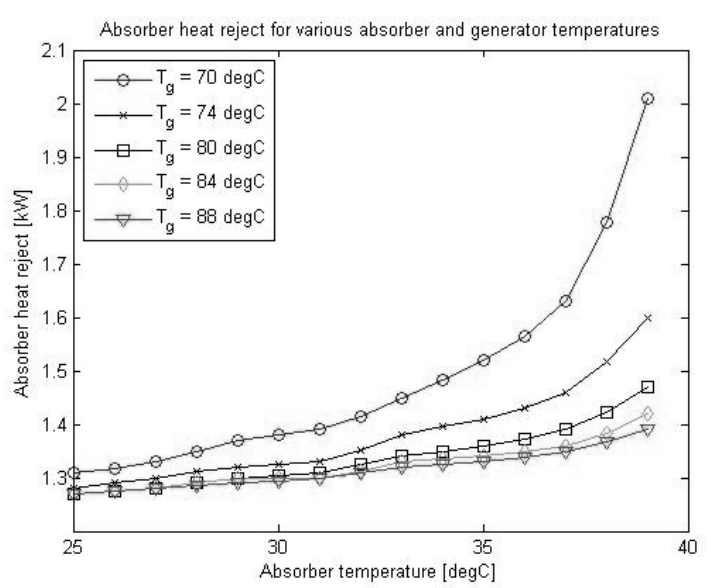

a)

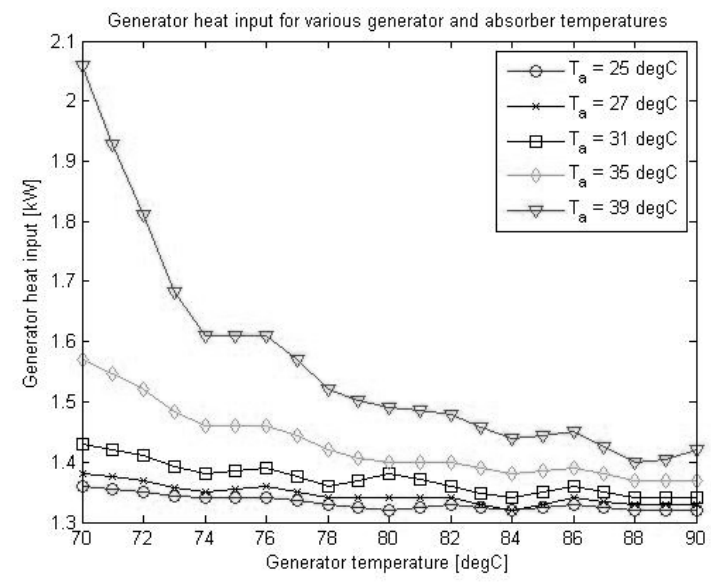

b)

Figure 6: $\mathrm{LiBr}-\mathrm{H}_{2} \mathrm{O}$ heat transfers for a condenser temperature of $30^{\circ} \mathrm{C}$.

a) Absorber heat reject against absorber temperature for various generator temperatures.

b) Generator heat input required against generator temperature for various absorber temperatures.

For the $\mathrm{H}_{2} \mathrm{O}-\mathrm{NH}_{3}$ case, the plots are shown in Fig. 7. The absorber heat reject shows a higher sensitivity to variations in absorber temperature. The curves for different generator temperatures in Fig. 7a overlap for the $T_{a}$ range of around 10 to $30^{\circ} \mathrm{C}$. For higher absorber temperatures the generator temperature becomes important to ensure low heat rejection requirements. In Fig. $7 \mathrm{~b}$ most of the graph show the features discussed in the previous COP analysis. The heat input requirements increase as generator temperature is increased due to the rectifier heat exchanger which causes a further heat loss. However as the absorber temperature is increased the trend shifts and a reduction in heat input required can be observed. This absorber temperature however should be nonetheless avoided due to the issues discussed in Fig. 7a. Also, in contrast to the $\mathrm{LiBr}-\mathrm{H}_{2} \mathrm{O}$ system, the generator heat input is sensitive to variations in absorber temperature for all the $T_{a}$ range. 


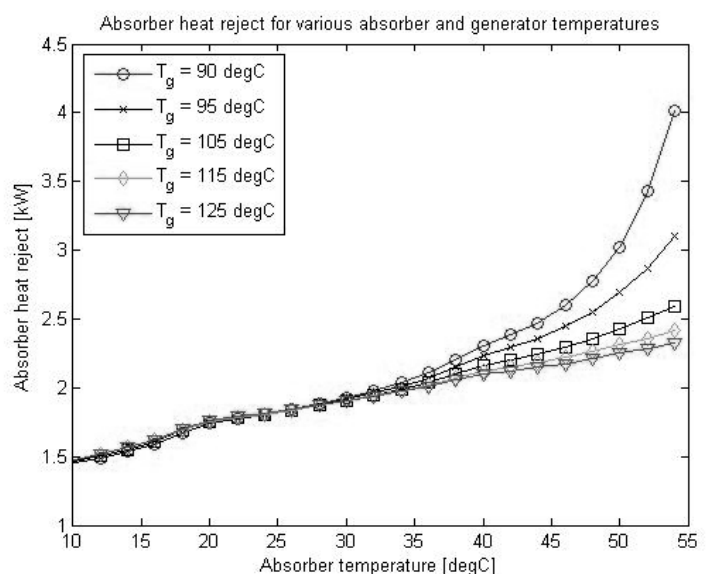

a)

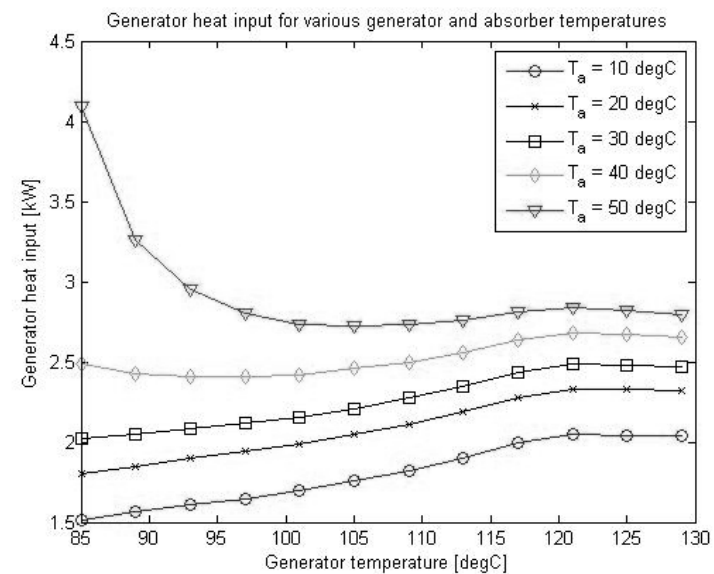

b)

Figure 7: $\mathrm{H}_{2} \mathrm{O}-\mathrm{NH}_{3}$ heat transfers for a condenser temperature of $30^{\circ} \mathrm{C}$.

a) Absorber heat reject against absorber temperature for various generator temperatures.

b) Generator heat input required against generator temperature for various absorber temperatures.

\section{CONCLUSIONS}

The simulation presented, is a useful tool for the thermodynamic analysis of vapour absorption systems. System designers may take advantage of the very simple user interface to obtain estimates of the system performance under predefined conditions. Apart from this, research and analysis could be performed by investigating the system behaviour to changes in input variables. In this paper, some results for both fluid pairs, when no solution heat exchanger is used, were obtained. The simulation has been successfully validated with a numerical example as well as with a similar simulation from [6]. In future work, it will also be validated against experimental data. The generalized mathematical model allows for easy extension to more complicated multi-effect systems.

A number of limitations have been pointed out throughout the paper. Particularly, the model is based on a number of fundamental assumptions. These are used to enable a closed system of equations and maintaining enough simplicity to be able to extend the program for analysis of more complicated systems. The fluid property database was obtained from graphical data and hence may be susceptible to some error. Since absorption system performance depends on several variables, it is difficult to investigate its behaviour by simultaneously varying each variable. In this study, the evaporator temperature had to be kept constant and the other temperatures varied accordingly to better understand the response of the system. COP contour maps were presented such that optimal operating regions could easily be identified. Plots of the absorber and generator heat transfers against the respective temperatures were also obtained from the simulation. This data will be crucial for further work. A vapour absorption system may use a solar heat input unit. The secondary fluid used for heat transfer may be susceptible to a temperature fluctuation throughout the day. The system performance will therefore highly depend on the rate of change of generator temperature. Regions of high gradients have been observed in dense contour line regions in this work. By means of this simulation these rates may be investigated numerically. 


\section{REFERENCES}

[1] Grossman, G.; Wilk, M. (1993). Enhanced Absorption Cycle Computer Model, Oak Technion Israel Institute of Technology \& Oak Ridge National Laboratory, ORNL/Sub/91-SH641/1

[2] Grossman, G.; Michelson, E. (1986). Absorption Heat Pump Simulation and Studies - A Modular Computer Simulation of Absorption Systems, Technion Israel Institute of Technology \& Oak Ridge National Laboratory, ORNL/Sub/83-43337/2

[3] Mittal, V.; Kasana, K.; Thakur, N. (2006). Modelling and simulation of a solar absorption cooling system for India, Journal of Energy in Southern Africa, Vol. 17, No. 3, 65-70

[4] Wang, S. K. (2001). Handbook of airconditioning and refrigeration, McGraw-Hill, New York

[5] Eastop, T.; McKonkey, A. (1993). Applied Thermodynamics for Engineering Technologists, Pearson Education Inc., Singapore

[6] American Society of Heating, Refrigerating and Air-Conditioning Engineers (2001). ASHRAE Fundamentals Handbook, ASHRAE, Atlanta

[7] Hudson, D. (2002). Ammonia Absorption Refrigeration Plant, The Official Journal of Airah, 2630

[8] Chaouachi, B.; Gabsi, S. (2007). Design and Simulation of an Absorption Diffusion Solar Refrigeration Unit, American Journal of Applied Sciences, Vol. 4, No. 2, 85-88

[9] Kim, D. S.; Infante Ferreira, C. A. (2005). Air Cooled Solar Absorption Air Conditioning, TU Delft, Report K-SOLAR 